\title{
Trends in clinical features, postoperative outcomes, and long-term survival for gastric cancer: a Western experience with 1,278 patients over 30 years
}

Fausto Rosa ${ }^{1 *}$, Sergio Alfieri ${ }^{1}$, Antonio Pio Tortorelli ${ }^{1}$, Claudio Fiorillo ${ }^{1}$, Guido Costamagna ${ }^{2}$ and Giovanni Battista Doglietto ${ }^{1}$

\begin{abstract}
Background: The aim of the present study was to identify temporal trends in long-term survival and postoperative outcomes and to analyze prognostic factors influencing the prognosis of patients with gastric cancer (GC) treated in a 30-year interval in a tertiary referral Western institution.

Methods: Between January 1980 and December 2010, 1,278 patients who were diagnosed with GC at the Digestive Surgery Department, Catholic University of Rome, Italy, were identified. Among them, 936 patients underwent surgical resection and were included in the analysis.
\end{abstract}

Results: Over time there was a significant improvement in postoperative outcomes. Morbidity and mortality rates decreased to $19.4 \%$ and $1.6 \%$, respectively, in the last decade. By contrast, the multivisceral resection rate steadily increased from $12.7 \%$ to $29.6 \%$. The overall five-year survival rate steadily increased over time, reaching $51 \%$ in the last decade, and $64.5 \%$ for $\mathrm{R} 0$ resections. Multivariate analysis showed a higher probability of overall survival for early stages (I and II), extended lymphadenectomy, and RO resections.

Conclusions: Over three decades there was a significant improvement in perioperative and postoperative care and a steady increase in overall survival.

Keywords: Gastric cancer, Surgery, Long-term survival

\section{Summary}

The aim of the present study was to identify, over a 30 year period, temporal trends in long-term survival and postoperative outcomes and to analyze prognostic factors influencing the prognosis of gastric cancer (GC) patients in a tertiary referral Western institution.

\section{Background}

Despite a major decline in incidence and mortality, gastric cancer (GC) remains an important public health burden worldwide. Nearly one million $(988,000)$ new cases of stomach cancer were recorded in 2008, accounting for $7.8 \%$ of all cancer cases. At the same time, 736,000 people

\footnotetext{
* Correspondence: faust.rosa@tiscali.it

'Department of Digestive Surgery, Catholic University, "A. Gemelli" Hospital, Largo A. Gemelli, 8, Rome 00168, Italy

Full list of author information is available at the end of the article
}

died from gastric cancer, representing 9.7\% of all cancer deaths. Hence, GC is the fourth most commonly occurring cancer after cancer of the lung, breast, and colonrectum, and the second most common cancer-related cause of death after lung cancer [1].

Over the past several decades, the epidemiologic profile of GC has changed dramatically. Although the incidence of $\mathrm{GC}$ is decreasing, the incidence of esophago-gastric junction (EGJ) cancer is increasing [2].

Survival after surgery of GC has been deeply studied in multiple series with patients stratified by stage of disease, Lauren tumor type, tumor location, time period, and administration of adjuvant therapy. All studies uniformly show an association between stage and survival. The Lauren classification significantly correlates with survival, in the fact that intestinal-type tumors are associated with longer survival than are diffuse-type tumors 
[3]. With regard to tumor location, some series show a significant association with survival, with GC having an improved prognosis over EGJ cancer $[2,3]$.

Screening and the widespread use of endoscopy have been shown to be effective in the early diagnosis of cancer $[4,5]$. Preoperative staging techniques have improved with time, allowing better selection of patients, while operative techniques and perioperative management have also evolved, leading to decreased morbidity and mortality [6,7]. Every day, new information emerges in the cancer field that has the potential to change cancer care.

In the light of these findings, we overviewed 1,278 patients with gastric cancer over a 30 -year period. The aim of the present study was to identify temporal trends in long-term survival and postoperative outcomes and to analyze prognostic factors influencing the prognosis of GC patients in a tertiary referral Western institution.

\section{Methods}

A review of the prospective database of GC at the Digestive Surgery Unit, Department of Surgery, Catholic University, Rome, Italy, identified 1,278 patients who were diagnosed with GC between January 1980 and December 2010. Institutional review board approval was obtained before review of the patients' medical records. Catholic University Institutional Review Board approved the study.

In order to demonstrate changes over time, the time trends were examined by comparing three time periods (1980-1989, 1990-1999, and 2000-2010). These three periods were chosen to achieve a balance of sufficient sample number and adequate follow-up.

Informed consent regarding surgical treatment, followup, and data management for research studies was obtained from all included patients.

We recorded hospital morbidity and mortality, type of treatment, histologic type according to Lauren [8], and demographic characteristics, tumor size, location, and gross appearance according to Borrmann [9]. The disease was staged according to the 7th Edition of the American Joint Committee on Cancer and the International Union Against Cancer Staging System (UICC) [10]. Based on categories established by the Japanese Gastric Cancer Association [11], the regional extent of nodal involvement after radical procedures was also recorded. Tumors located proximally were classified according to Siewert and Stein [12]. Only Siewert type III tumors were included in the analysis.

All patients with potentially curable lesions were treated by gastrectomy and D2 lymphadenectomy. Patients with stage IV disease and noncurable lesions (distant metastases, peritoneal carcinomatosis, and N4 nodal involvement) at the preoperative evaluation were either treated by palliative gastrectomy and perigastric (D1) lymphadenectomy with the intent to control specific symptoms (bleeding and/or obstruction) and to obtain survival advantage or, in the last period, patients with bulky nodal disease received perioperative chemotherapy.

For tumors located in the middle and lower thirds of the stomach, a subtotal gastrectomy was generally preferred, provided that an adequate resection margin was maintained. Gastrectomy was always completed by removal of the greater omentum and perigastric lymph nodes; extended lymphadenectomy was performed according to the criteria subsequently described by the Japanese Gastric Cancer Association [11].

The reconstruction of digestive continuity after total gastrectomy was previously described [13]. After subtotal distal gastrectomy, a gastrojejunostomy according to the Billroth II operation was usually performed. In case of upper polar resection (with or without transhiatal/ abdominothoracic esophagectomy), an esophagogastrostomy was performed, manually until the early 1980s and later using a 25-mm mechanical circular stapler with a row of external seromuscular sutures with interrupted absorbable stitches.

Resection was stated as potentially curative (R0 according to the UICC) if macro- and microscopically no tumor was left following surgery [10].

Extensive surgery (multiorgan resection) because of suspicion of direct tumor invasion was defined as combined resection of adjacent organs (spleen, left pancreas, liver, colon, adrenal gland, diaphragm, abdominal wall, and small intestine).

At the end of the operation, the surgeon resected all lymph nodes from the surgical specimen and identified their distribution and tumor location according to the classification subsequently described by the Japanese Gastric Cancer Association [11].

The patients were monitored for 30-day postoperative complications and mortality.

As far as combined treatments are concerned, 28 patients, all in the third period (2000-2010), received perioperative neoadjuvant therapy according to the MRC Adjuvant Gastric Infusional Chemotherapy (MAGIC) protocol [14].

Three hundred sixty-one patients received postoperative adjuvant therapy. Adjuvant regimens were highly varied over the 30 years spanned by this series. As previously reported [13], the decision to administer adjuvant chemotherapy was made by medical oncologists. This resulted in heterogeneous indications for chemotherapy, treatment protocols, and number of cycles performed.

Therefore, details of adjuvant and neoadjuvant chemotherapy were not considered for statistical analysis.

\section{Statistical analysis}

All clinical and pathological data were prospectively stored in a GC database and retrospectively evaluated for this study.

Patient status was investigated by follow-up examination or by telephone contact. Complete follow-up information 
was obtained as of 30 September 2012. The complete follow-up rates from 1980-1989, 1990-1999, and 20002010 were $95 \%$, 97\%, and 98\%, respectively.

Statistical analysis was performed using commercially available software $\left(\mathrm{SPSS}^{\odot}\right.$ for Windows version 20.0; Chicago, IL). Results are given as mean (SD). The statistical significance of the difference between mean values was evaluated using the Student's $t$-test. All tests were two tailed. Categorical variables were assessed by the Pearson's chi-squared test. Multivariable analysis was undertaken using the Cox proportional hazards model. Survival curves were estimated using the Kaplan-Meier method, and differences between groups were evaluated using the log-rank test. $P<0.05$ was considered statistically significant.

\section{Results}

Among 1,278 patients, 90 patients were not resected and were addressed to palliative therapies, 147 were found on exploration to have irresectable disease, and 105 received just a bypass procedure. Gastrectomy was possible in the remaining 936 patients, resulting in an overall resectability rate of $73.2 \%$.

All 936 patients were included in the analysis: $n=275$ in the period 1980-1989, $\mathrm{n}=239$ in the period 19901999 , and $n=422$ in the period 2000-2010.

The different types of surgical procedures are reported in Table 1. After a decline in observation in the 1990s for GC, in the period 2000-2010 there was an exponential increase.

The patient characteristics are given in Table 2 .

As expected, some characteristics differed between the three treatment periods.

The most common tumor location was the lower third in 405 (43.2\%) patients for all three periods, followed by the middle third in 337 (36\%), the upper third in 179 (19.1\%), and the whole stomach in 15 (1.6\%).

Histologic evaluation was available for all the resected specimens. Most carcinomas showed intestinal type differentiation ( $47.9 \%$ for the three periods) with a significant difference between the first and the third decade (39.6\% versus $50.8 \% ; P<0.001)$.
In our experience, stage I GC significantly increased over time with a significant reduction of stages III and IV $(P<0.001)$.

Surgical characteristics according to treatment period are reported in Table 3.

The most common operations were total gastrectomy (48\%), subtotal distal gastrectomy (46.3\%), total degastrogastrectomy (3.8\%), and proximal resections (upper polar resection with or without transhiatal/abdominothoracic esophagectomy) (1.9\%).

Total gastrectomy was the most common procedure in the second decade, whereas subtotal distal gastrectomy was most common in the first and third decades.

Overall, 723 patients were categorized as R0 resections (77.2\%). There were no significant differences in these data concerning the three time intervals.

Noncurative resections were performed in 213 patients (22.8\%).

Overall morbidity and mortality were $25.3 \%$ and $3.7 \%$, respectively.

Over time, multivisceral resections and lymph nodes retrieved constantly increased over the three periods, but did not result in higher morbidity and mortality.

Factors affecting five-year overall survival according to univariate and multivariate analysis are reported in Tables 4 and 5, respectively.

The overall median survival was 52 months. The median survival in the three time periods was 37,54 , and 68 months, respectively.

The five-year overall survival for the three periods was $39 \%$, $48 \%$, and $51 \%$, respectively (period $1980-1989$ versus 1990-1999/2000-2010) $P<0.001$; ten-year overall survival for the three periods was $27 \%, 42 \%$, and $42 \%$, respectively, $P<0.001$ (period 1980-1989 versus 1990-1999/20002010). See Figure 1.

Over time there was an improvement in the R0 fiveyear survival rate: the survival significantly increased from $51 \%$ to $64.5 \%(P<0.001)$. See Figure 2 .

Survival was strongly associated with tumor location, tumor stage, R-classification, and lymph node dissection at univariate analysis.

Table 1 Patients observed (1980-2010)

\begin{tabular}{|c|c|c|c|c|c|}
\hline Surgical procedure & $1980-1989(n=440)$ & $1990-1999(n=320)$ & $2000-2010(n=518)$ & $1980-2010(n=1,278)$ & Resected (936) \\
\hline Total gastrectomy & $128(29.1)$ & $140(43.8)$ & $182(35.1)$ & $450(35.2)$ & \\
\hline Subtotal distal gastrectomy & 139 (31.6) & $90(28.1)$ & $204(39.4)$ & $433(33.9)$ & \\
\hline Total degastro-gastrectomy & $5(1.1)$ & $9(2.8)$ & $21(4)$ & $35(2.7)$ & \\
\hline Upper polar resection & $3(0.7)$ & $0(0)$ & $15(2.9)$ & $18(1.4)$ & \\
\hline Bypass procedure & $69(15.7)$ & $19(5.9)$ & $17(3.3)$ & $105(8.2)$ & \\
\hline Exploratory laparotomy & $50(11.3)$ & $34(10.6)$ & $63(12.2)$ & $147(11.5)$ & \\
\hline No surgery & 46 (10.6) & $28(8.8)$ & $16(3.1)$ & $90(7.1)$ & \\
\hline
\end{tabular}

Values in bold are percentages. 
Table 2 Details of patient and tumor characteristics in 936 patients undergoing tumor resection

\begin{tabular}{|c|c|c|c|c|c|}
\hline & All patients $(n=936)$ & $1980-1989(n=275)$ & $1990-1999(n=239)$ & $2000-2010(n=422)$ & $P^{*}$ \\
\hline \multicolumn{6}{|l|}{ Gender } \\
\hline Male & $581(62)$ & $176(64)$ & $150(62.7)$ & $255(60.4)$ & \multirow[t]{2}{*}{0.63} \\
\hline Female & $355(38)$ & $99(36)$ & 89 (37.3) & 167 (39.6) & \\
\hline \multicolumn{6}{|l|}{ Age (years) } \\
\hline$<65$ & $503(53.7)$ & $153(55.6)$ & $129(54)$ & $221(52.4)$ & \multirow[t]{2}{*}{0.70} \\
\hline$\geq 65$ & $433(46.3)$ & $122(44.4)$ & $110(46)$ & $201(47.6)$ & \\
\hline \multicolumn{6}{|l|}{ Tumor location } \\
\hline Lower third & $405(43.2)$ & $131(47.6)$ & $102(42.7)$ & $172(40.7)$ & \multirow[t]{4}{*}{0.31} \\
\hline Middle third & $337(36)$ & $90(32.7)$ & $82(34.3)$ & $165(39)$ & \\
\hline Upper third & $179(19.1)$ & $52(18.9)$ & $49(20.5)$ & 78 (18.5) & \\
\hline Whole stomach & $15(1.6)$ & $2(0.2)$ & $6(2.5)$ & $7(1.6)$ & \\
\hline \multicolumn{6}{|l|}{ Tumor stage } \\
\hline 1 & $255(27.2)$ & $48(17.4)$ & $68(28.4)$ & $139(33)$ & \\
\hline$\|$ & $197(21)$ & $70(25.4)$ & $32(13.4)$ & $95(22.5)$ & \multirow[t]{3}{*}{$<0.001$} \\
\hline III & 319 (34) & $97(35.3)$ & 88 (36.8) & $134(31.7)$ & \\
\hline IV & $165(17.6)$ & $60(21.8)$ & $51(21.3)$ & $54(12.8)$ & \\
\hline \multicolumn{6}{|l|}{ Lauren classification } \\
\hline Diffuse & $402(42.9)$ & $138(50.2)$ & $105(43.9)$ & 159 (37.6) & \\
\hline Intestinal & $449(48)$ & $109(39.6)$ & $126(52.7)$ & $214(50.8)$ & \multirow[t]{2}{*}{$<0.001$} \\
\hline Indeterminate & $85(9.1)$ & $28(10.2)$ & $8(3.4)$ & 49 (11.6) & \\
\hline \multicolumn{6}{|l|}{ Borrmann classification } \\
\hline । & $192(20.5)$ & $59(21.5)$ & $49(20.5)$ & $84(19.9)$ & \multirow[t]{5}{*}{0.83} \\
\hline$\|$ & $316(33.8)$ & $80(29.1)$ & 78 (32.6) & $158(37.4)$ & \\
\hline III & $276(29.5)$ & $92(33.4)$ & $83(34.7)$ & $101(23.9)$ & \\
\hline IV & $137(14.6)$ & $38(13.8)$ & $27(11.4)$ & $72(17.1)$ & \\
\hline Undetermined & $15(1.6)$ & $6(2.2)$ & $2(0.8)$ & $7(1.7)$ & \\
\hline Tumor size, mean (SD), cm & $4.9 \pm 3.6$ & $6.5 \pm 4.1$ & $4.4 \pm 2.7$ & $4.2 \pm 2.8$ & $<0.001$ \\
\hline Distant metastasis & $74(7.9)$ & $20(7.3)$ & $17(7.1)$ & $37(8.8)$ & 0.635 \\
\hline
\end{tabular}

Values in parentheses are percentages. *Two-tailed Pearson's chi-squared test.

For stage III cancer there was a $10 \%$ increase (from 28 to $38 \% ; P=0.024)$. A significant increase of five-year survival was encountered for patients with less than 15 lymph nodes retrieved (from 22.4 to $39.2 \% ; P<0.001$ ) as well.

In multivariate analysis, tumor stage, lymphadenectomy, and margin status were independent prognostic indicators.

\section{Discussion}

In this large Western single institution series, GC characteristics, surgical approaches, and long-term results were analyzed over a period of 30 years in a tertiary care hospital.

Throughout the world, stomach cancer is a disease of the elderly population with a predominance in men [15].
The mean age and male predominance of the patients in our series are similar to those in other reports $[13,15,16]$.

Trend analyses in our study showed no changes in mean age or gender proportions over the years.

Usually, postoperative outcomes in Western centers have been explained by the difference in age, weight, and comorbidity, whereas the poor long-term survival has been attributed to tumor stage and location $[16,17]$.

In contrast with other reports in the literature [17-21], in our experience we observed a constant increase of middle third location with respect to upper third location. The significant increase, between the second and the third decade, in subtotal distal gastrectomies may be partially explained by a different attitude to perform a partial gastrectomy rather than a total gastrectomy in the case of a middle third location. 
Table 3 Surgical characteristics according to treatment period

\begin{tabular}{|c|c|c|c|c|c|}
\hline & Whole series $(n=936)$ & $1980-1989(n=275)$ & $1990-1999(n=239)$ & $2000-2010(n=422)$ & $P^{*}$ \\
\hline \multicolumn{6}{|l|}{ Extent of resection } \\
\hline Total gastrectomy & $450(48)$ & $128(46.6)$ & $140(58.6)$ & $182(43.1)$ & \multirow[t]{4}{*}{$<0.001$} \\
\hline Subtotal distal gastrectomy & $433(46.3)$ & $139(50.5)$ & $90(37.6)$ & $204(48.4)$ & \\
\hline Total degastro-gastrectomy & $35(3.8)$ & $5(1.8)$ & $9(3.8)$ & $21(5)$ & \\
\hline Upper polar resection & $18(1.9)$ & $3(1.1)$ & 0 & $15(3.5)$ & \\
\hline \multicolumn{6}{|l|}{ Margin status } \\
\hline Ro & $723(77.2)$ & $213(77.5)$ & $178(74.5)$ & $336(79.6)$ & \multirow[t]{2}{*}{0.689} \\
\hline $\mathrm{R} 1 / 2$ & $213(22.8)$ & $62(22.5)$ & $61(25.5)$ & $90(21.4)$ & \\
\hline Multivisceral resections & $195(21)$ & $35(12.7)$ & $37(15.5)$ & $123(29.6)$ & $<0.001$ \\
\hline \multicolumn{6}{|l|}{ Lymph nodes retrieved } \\
\hline$<15$ & $225(24)$ & $114(41.5)$ & $31(13)$ & $71(16.8)$ & \multirow[t]{3}{*}{$<0.00$} \\
\hline $15-30$ & $327(35)$ & $84(30.5)$ & $66(27.6)$ & $157(37.2)$ & \\
\hline$\geq 30$ & $384(41)$ & $77(28)$ & $142(59.4)$ & $194(46)$ & \\
\hline Perioperative morbidity** & $230(25.3)$ & $74(26.9)$ & $72(30.1)$ & $82(19.4)$ & 0.004 \\
\hline Anastomotic leak & $39(4.2)$ & $8(2.9)$ & $15(6.3)$ & $16(3.8)$ & \\
\hline Intra-abdominal abscess & $27(2.9)$ & $11(4)$ & $11(4.6)$ & $5(1.2)$ & \\
\hline Abdominal wound dehiscence & $4(0.4)$ & $2(0.7)$ & $1(0.4)$ & $1(0.2)$ & \\
\hline Wound infection & $11(1.2)$ & $8(2.9)$ & $2(0.8)$ & $1(0.2)$ & \\
\hline Duodenal stump dehiscence & $6(0.6)$ & $3(1)$ & 0 & $3(0.7)$ & \\
\hline Pneumonia & $31(3.3)$ & $13(4.7)$ & $8(3.3)$ & $10(2.4)$ & \\
\hline Pulmonary embolism & $5(0.5)$ & $3(1)$ & $1(0.4)$ & $1(0.2)$ & \\
\hline Hemorrhage & $26(2.8)$ & $1(0.4)$ & $10(4.2)$ & $15(3.5)$ & \\
\hline Pancreatic fistula & $10(1)$ & $2(0.7)$ & $5(2)$ & $3(0.7)$ & \\
\hline Intestinal obstruction & $3(0.3)$ & $2(0.7)$ & 0 & $1(0.2)$ & \\
\hline Melena & $3(0.3)$ & $1(0.4)$ & $1(0.4)$ & $1(0.2)$ & \\
\hline Other & $69(7.4)$ & $23(8.4)$ & $18(7.5)$ & $28(6.6)$ & \\
\hline Perioperative mortality & $33(3.7)$ & $17(6.2)$ & $10(4.2)$ & $6(1.6)$ & 0.009 \\
\hline
\end{tabular}

Values in parentheses are percentages. *Two-tailed Pearson's chi-squared test. **The total number of patients having complications is less than the sum of patients having individual complications because some patients had more than one complication.

The highly significant difference in tumor stage between time periods is undoubtedly related to the widespread use of endoscopy in case of gastric symptoms, which resulted in earlier diagnosis.

Over time, we assisted to a significant decrease in perioperative mortality and overall complications; $P=0.009$ and $P=0.004$, respectively.

Anesthesiological improvements have significantly reduced perioperative death to a minimum, and support is readily available in the intensive care unit if postoperative organ failure occurs. Besides these general improvements in perioperative care, the refinement of the surgical technique may also have contributed to improve early results after gastrectomy. The introduction of the pancreas-preserving procedure [22], the avoidance of splenectomy if unnecessary, and the evolution of anastomotic techniques have reduced the incidence of postoperative surgical complications [23,24].
Over the three decades, survival for the present study was significantly better with respect to other Western experiences $[17,18,21]$.

In this study, we compared survival rates of patients with resected GC after stratification by time periods. Our results largely agree much more with Eastern series [25] than with previously reported Western experiences [26-28].

Karpeh et al. [19], for example, reported the overall fveyear survival rate after R0 resection for GC to be $49 \%$.

Marrelli et al. [18], in a large multicenter Italian observational study, had concluded that five-year survival rates after R0 resection (2,320 patients) did not change over time; moreover, a mild decrease in survival in more recent years was related to more advanced stages, distal tumors, and tumors in women. Marrelli et al. reported a five-year overall survival rate of $54.7 \%$; $51.2 \%$ in the most recent period. 
Table 4 Factors affecting five-year overall survival according to univariate analysis

\begin{tabular}{|c|c|c|c|c|c|}
\hline & \multirow[b]{2}{*}{ All patients $(n=936)$} & \multicolumn{4}{|c|}{ Five-year overall survival (\%) } \\
\hline & & 1980-1989 & 1990-1999 & 2000-2010 & $P^{*}$ \\
\hline \multicolumn{6}{|l|}{ Gender } \\
\hline Male & $581(62)$ & 39.6 & 46.6 & 51.3 & $<0.001$ \\
\hline Female & $355(38)$ & 37.8 & 52.2 & 53.4 & 0.02 \\
\hline \multicolumn{6}{|l|}{ Age } \\
\hline$<65$ & $503(53.7)$ & 45.8 & 53 & 55 & 0.001 \\
\hline$\geq 65$ & $433(46.3)$ & 31.1 & 42 & 47 & 0.004 \\
\hline \multicolumn{6}{|l|}{ Tumor location } \\
\hline Lower third & $405(43.3)$ & 40.2 & 50.5 & 54.5 & 0.003 \\
\hline Middle third & $337(36)$ & 46.2 & 59.5 & 57.9 & 0.03 \\
\hline Upper third & $179(19.1)$ & 27 & 30.6 & 38.1 & 0.03 \\
\hline Whole stomach & $15(1.6)$ & 18 & 25.3 & 33.4 & 0.027 \\
\hline \multicolumn{6}{|l|}{ Lauren classification } \\
\hline Diffuse & $402(42.9)$ & 32.8 & 47.5 & 47 & 0.003 \\
\hline Intestinal & $449(48)$ & 48.8 & 48.1 & 59.1 & 0.017 \\
\hline Indeterminate & $85(9.1)$ & 37 & 34.3 & 35 & 0.18 \\
\hline \multicolumn{6}{|l|}{ Tumor stage } \\
\hline । & $255(27.2)$ & 77 & 74.9 & 76.8 & 0.035 \\
\hline$\|$ & $197(21.1)$ & 51.2 & 61.6 & 67.1 & 0.075 \\
\hline III & $319(34.1)$ & 28.5 & 31.4 & 38.7 & 0.024 \\
\hline IV & $165(17.6)$ & 11.9 & 10.6 & 14.6 & 0.320 \\
\hline \multicolumn{6}{|l|}{ Type of gastrectomy } \\
\hline Total gastrectomy & $450(48)$ & 43.9 & 46.5 & 50.8 & 0.12 \\
\hline Distal subtotal gastrectomy & $433(46.2)$ & 45.9 & 51.6 & 57.6 & $<0.001$ \\
\hline \multicolumn{6}{|l|}{ Margin status } \\
\hline RO & $723(77.2)$ & 51 & 60.5 & 64.5 & $<0.001$ \\
\hline $\mathrm{R} 1 / 2$ & $213(22.8)$ & 20 & 23 & 26 & 0.158 \\
\hline \multicolumn{6}{|l|}{ Adjuvant therapy } \\
\hline Yes & $361(39)$ & 27.2 & 29.6 & 35.2 & 0.138 \\
\hline No & $571(61)$ & 56.1 & 57 & 55.3 & 0.286 \\
\hline Multivisceral resections & $195(21)$ & 24.9 & 31.7 & 49.6 & $<0.001$ \\
\hline \multicolumn{6}{|l|}{ Lymph nodes retrieved } \\
\hline$<15$ & $225(24)$ & 22.4 & 30.4 & 39.2 & $<0.001$ \\
\hline $15-30$ & $327(35)$ & 48.6 & 43.7 & 50.7 & 0.279 \\
\hline$\geq 30$ & $384(41)$ & 59 & 58.8 & 64 & 0.03 \\
\hline
\end{tabular}

Values in parentheses are percentages. *Log-rank test.

In a large meta-analysis of 100 English-language publications since 1970, Akoh and Macintyre [29] found survival to improve from early to later time periods.

In the current study, we found a significant improvement in survival among the three study periods $(P<0.001)$ comparing period 1 versus periods 2 and 3 .

First of all, this improvement is undoubtedly related to the increased number of early gastric cancers due to the widespread use of endoscopy in the case of gastric symptoms. Moreover, the increase in long-term survival after curative gastrectomy is probably related to our maximum effort to effect a surgical cure. $\mathrm{N}$ and $\mathrm{R}$ variables were addressed by routine extended lymphadenectomy. R0 resection was obtained in $77.2 \%$ of patients, and most of them received an extended lymphadenectomy. 
Table 5 Significant prognostic factors evaluated by Cox proportional hazards analysis

\begin{tabular}{|c|c|c|}
\hline & \multicolumn{2}{|l|}{ Overall survival } \\
\hline & Hazard ratio & $P$ \\
\hline \multicolumn{3}{|l|}{ Tumor location } \\
\hline Lower third & $0.54(0.26-1.11)$ & 0.095 \\
\hline Middle third & $0.53(0.25-1.09)$ & 0.08 \\
\hline Upper third & $0.91(0.43-1.9)$ & 0.8 \\
\hline Whole stomach & 1 & \\
\hline \multicolumn{3}{|l|}{ Tumor stage } \\
\hline । & $0.15(0.08-0.28)$ & $<0.001$ \\
\hline$\|$ & $0.35(0.2-0.62)$ & $<0.001$ \\
\hline III & $0.69(0.41-1.15)$ & 0.16 \\
\hline IV & 1 & \\
\hline \multicolumn{3}{|c|}{ Treatment period } \\
\hline 1980-1989 & $1.25(0.95-1.65)$ & 0.1 \\
\hline 1990-1999 & $1.02(0.76-1.36)$ & 0.86 \\
\hline 2000-2010 & 1 & \\
\hline \multicolumn{3}{|c|}{ Lauren classification } \\
\hline Diffuse & $1.34(0.86-1.73)$ & 0.78 \\
\hline Indeterminate & $1.52(1.2-1.81)$ & 0.41 \\
\hline Intestinal & 1 & \\
\hline \multicolumn{3}{|c|}{ Lymph nodes retrieved } \\
\hline$<15$ & $2.41(1.07-2.86)$ & \\
\hline $15-30$ & $1.34(1.02-2.15)$ & 0.009 \\
\hline$\geq 30$ & 1 & \\
\hline \multicolumn{3}{|c|}{ Patients with complications } \\
\hline Yes & $1.19(0.93-1.5)$ & 0.156 \\
\hline No & 1 & \\
\hline \multicolumn{3}{|c|}{ Multivisceral resections } \\
\hline Yes & $1.07(0.81-1.43)$ & 0.609 \\
\hline No & 1 & \\
\hline \multicolumn{3}{|l|}{ Margin status } \\
\hline $\mathrm{R} 1 / \mathrm{R} 2$ & $1.97(1.2-3.1)$ & 0.003 \\
\hline RO & 1 & \\
\hline
\end{tabular}

Values in parentheses are $95 \%$ confidence intervals.

The mean number of dissected nodes per operative specimen was high. Appropriate training in the techniques of extended lymphadenectomy is essential. The clearance of appropriate lymph node stations was not compromised by case difficulty, and accurate staging and optimization by a multidisciplinary team are essential. Appropriate management of postoperative complications is crucial to minimize mortality. A meta-analysis of six randomized controlled trials totalling 1,876 patients concluded that D2 gastrectomy is associated with higher 30-day mortality and more postoperative complications and with a five-year survival similar to that of the D1 cohort [30].

However, experienced groups from Japanese [31,32] and Western $[13,33,34]$ institutions continue to perform complete D2 lymph node dissection, reporting low complication rates and survival advantages. Similar results have been obtained in recently published prospective studies $[35,36]$.

Extended lymphadenectomy leads to improved long-term survival without compromising postoperative outcomes.

Multivariate analysis revealed a strict correlation between the number of lymph nodes removed and survival advantages; therefore, we can conclude that the number of lymph nodes dissected is significantly indicative of the quality of surgery [37].

Conversely, the constant increase in survival for patients with stage III cancer and for those with fewer than 15 lymph nodes removed is probably due to the positive effects of chemotherapy regimens based on epirubicin, cisplatin, and fluorouracil adopted in our center.

With respect to the Lauren classification of tumor type, at univariate analysis we found that the survival of patients with diffuse-type histology was significantly lower than that of patients with intestinal-type histology, but only in the third decade. This is consistent with published studies that do not exclude EGJ tumors from the analysis [38]. It is an important consideration, because tumors in the EGJ are more likely to be of the diffuse-type histology with a correspondingly poorer prognosis.

In the present series, we note a steady increase in survival, over time, both for diffuse-type and intestinal-type histology, $P=0.003$ and $P=0.017$, respectively.

Regarding the association between tumor location and survival, conflicting data exist. Studies that eliminate EGJ tumors, for example, find no significant association between survival and tumor location [38,39].

However, other studies that included EGJ tumors in the analysis have found that distal tumors are associated with an improved prognosis compared with proximal tumors $[40,41]$. The major determinants of the poor prognosis of proximal GC with respect to distal GC rely both on the more advanced age and tumor stage at the moment of clinical presentation and on the higher postoperative morbidity for patients with proximal GC.

Our series seems to confirm this latter position, excluding from the analysis EGJ tumors.

The constant increase of multivisceral resections in our series can be explained by the more aggressive surgical approach in the case of locally advanced GC and in the suspicion of direct invasion of adjacent organs. As reported by a recent Italian multicenter observational study [42], patients undergoing extended resections 


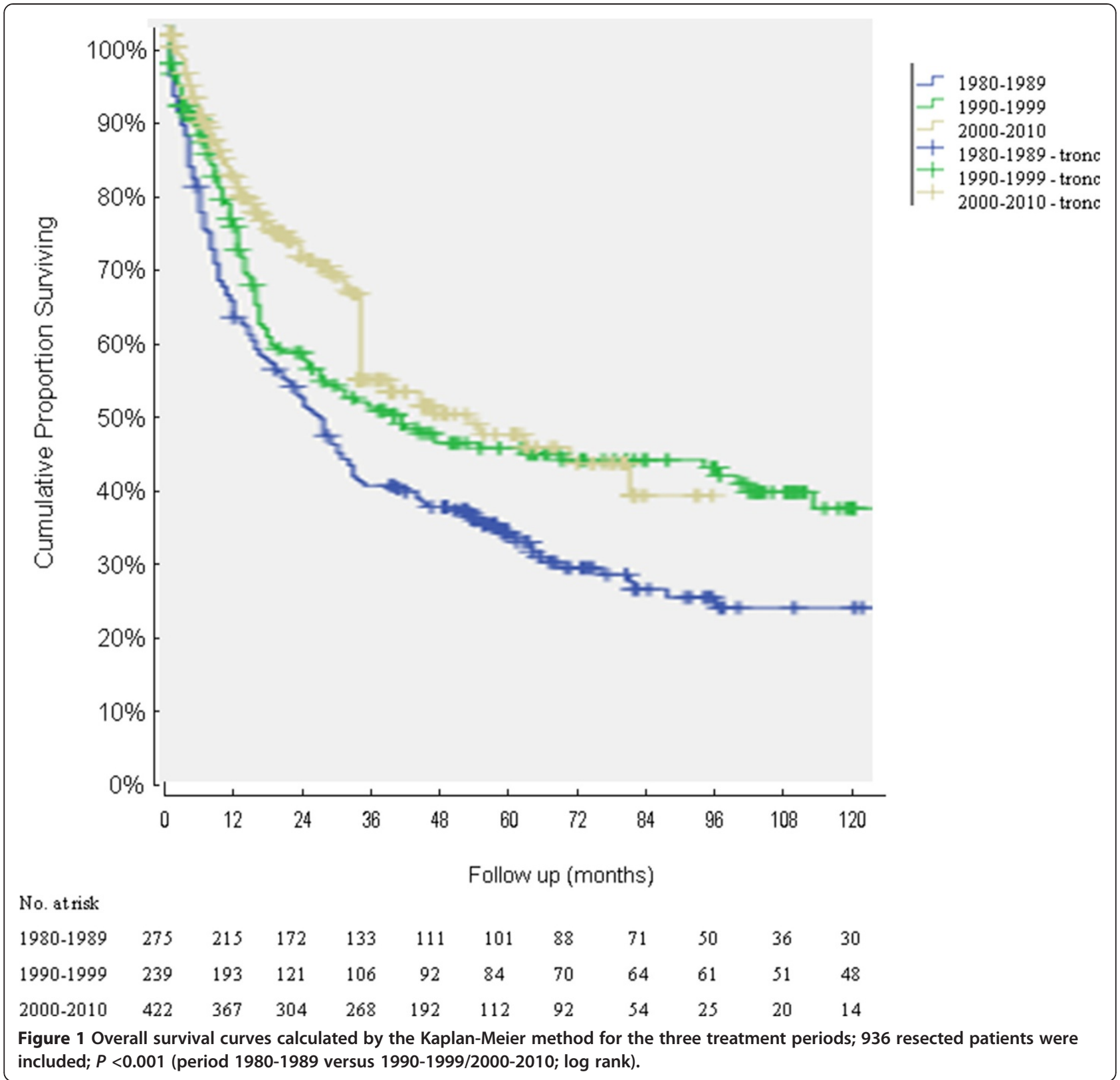

experience acceptable postoperative morbidity and mortality rates, and an en bloc multivisceral resection should be performed in patients when a complete resection can be realistically obtained and when lymph node metastasis is not evident.

The main limitations of this study include the following: 1) outcomes are from a single institution; 2) the study has a retrospective nature, which precludes the controlled acquisition and real-time verification of data that benefit prospective series; 3) follow-up is incomplete (less than five years) for a few patients of the last decade; 4) neoadjuvant and adjuvant treatment data are heterogeneous; and 5) quality-of-life data are absent.
In our retrospective study, we observed no significant improvement in survival with adjuvant therapy, likely due to the lack of a uniform regimen over the study's 30 -year period. In any case, the potential benefit of postoperative adjuvant chemotherapy is still unclear [43].

Twenty-eight patients who received neoadjuvant chemotherapy according to the MAGIC protocol were not taken into consideration for statistical analysis because they were all included in the last decade.

Significant survival improvement with perioperative therapies has been reported, and this treatment may be particularly useful for tumors with serosal involvement or advanced lymph node spread [14]. 


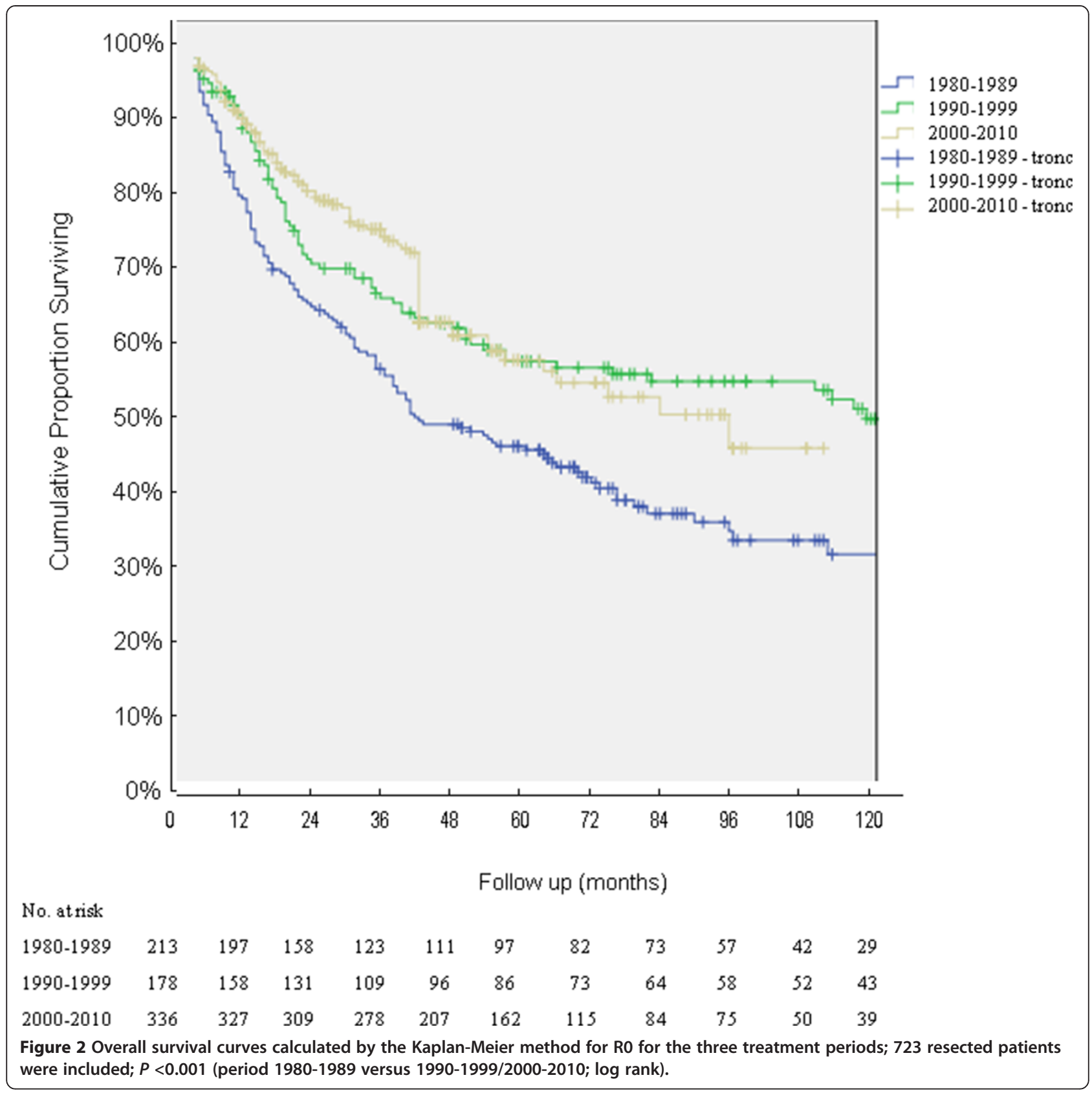

\section{Conclusions}

In conclusion, in our experience in the treatment of GC patients over three decades, we have observed a significant improvement in perioperative and postoperative care and a steady increase in overall survival.

Promising results are expected by the constant use of neoadjuvant regimens for locally advanced diseases.

Moreover, in the near future, we might expect some improvements in terms of quality of life from the increasingly widespread use of endoscopic dissection for early GC and minimally invasive surgical therapies.

\section{Competing interests}

The authors declare that they have no competing interests.

\section{Authors' contributions}

FR drafted the manuscript and searched the literature. SA, GBD and GC participated in the design of this study and critically revised the manuscript for important intellectual content. APT and CF performed the statistical analysis and collected important background information. All authors read and approved the final manuscript.

\section{Disclosure}

The results of this manuscript were presented as a free presentation at the 10th International Gastric Cancer Congress held in Verona (Italy) on 19-22 June 2013 


\section{Author details}

"Department of Digestive Surgery, Catholic University, "A. Gemelli" Hospital, Largo A. Gemelli, 8, Rome 00168, Italy. 'Department of Digestive Endoscopy, Catholic University, "A. Gemelli" Hospital, Rome, Italy.

Received: 21 March 2014 Accepted: 4 July 2014

Published: 16 July 2014

\section{References}

1. Ferlay J, Shin HR, Bray F, Forman D, Mathers C, Parkin DM: I: GLOBOCAN 2008, Cancer Incidence and Mortality Worldwide: IARC Cancer-Base No. 10 [Internet]. Lyon, France: International Agency for Research on Cancer; 2010. Available from http://globocan.iarc.fr.

2. Brown LM, Devesa SS: Epidemiologic trends in esophageal and gastric cancer in the United States. Surg Oncol Clin N Am 2002, 11:235-256.

3. Marrelli D, Roviello F, de Manzoni G, Morgagni P, Di Leo A, Saragoni L, De Stefano A, Folli S, Cordiano C, Pinto E, Italian Research Group for Gastric Cancer: Different patterns of recurrence in gastric cancer depending on Lauren's histological type: longitudinal study. World J Surg 2002, 26:1160-1165.

4. Kubota H, Kotoh T, Masunaga R, Dhar DK, Shibakita M, Tachibana M, Kohno H, Nagasue N: Impact of screening survey of gastric cancer on clinicopathological features and survival: retrospective study at a single institution. Surgery 2000, 128:41-47.

5. Kim YS, Park HA, Kim BS, Yook JH, Lee MS: Efficacy of screening for gastric cancer in a Korean adult population: a case-control study. J Korean Med Sci 2000, 15:510-515.

6. Borch K, Jonsson B, Tarpila E, Franzén T, Berglund J, Kullman E, Franzén L: Changing pattern of histological type, location, stage and outcome of surgical treatment of gastric carcinoma. Br J Surg 2000, 87:618-626.

7. Machara Y, Kakeji Y, Oda S, Takahashi I, Akazawa K, Sugimachi K: Time trends of surgical treatment and the prognosis for Japanese patients with gastric cancer. Br J Cancer 2000, 83:986-991.

8. Lauren P: The two histological main types of gastric cancer carcinoma: diffuse and so-called intestinal-type carcinoma. Acta Pathol Microbiol scand 1965, 64:31-49.

9. Borrmann R: Geschwulste des Magens und Duodenums. In Handbuch der Speziellen Pathologischen Anatomie und Histologie, Volume 4. Edited by Henke F, Lubarsch O. Berlin, Germany: J Springer; 1926:812-1054.

10. Sobin LH, Gospodarowicz MK, Wittekind C: International Union Against Cancer (UICC) TNM Classification of Malignant Tumors. 7th edition. New York: Wiley-Liss; 2010

11. Japanese Gastric Cancer Association: Japanese classification of gastric carcinoma: 2nd English edition. Gastric Cancer 1998, 1(1):10-24.

12. Siewert JR, Stein HJ: Classification of carcinoma of the oesophagogastric junction. Br J Surg 1998, 85:1457-1459.

13. Pacelli F, Papa V, Rosa F, Tortorelli AP, Sanchez AM, Covino M, Bossola M, Doglietto GB: Four hundred consecutive total gastrectomies for gastric cancer: a single-institution experience. Arch Surg 2008, 143:769-775.

14. Cunningham D, Allum WH, Stenning SP, Thompson JN, Van de Velde CJ, Nicolson M, Scarffe JH, Lofts FJ, Falk SJ, Iveson TJ, Smith DB, Langley RE, Verma M, Weeden S, Chua YJ, MAGIC Trial Participants: Perioperative chemotherapy versus surgery alone for resectable gastroesophageal cancer. N Engl JMed 2006, 355:11-20.

15. Brenner $H$, Rothenbacher $D$, Arndt $V$ : Epidemiology of stomach cancer. Methods Mol Biol 2009, 472:467-477.

16. Hanna GB, Boshier PR, Knaggs A, Goldin R, Sasako M: Improving outcomes after gastroesophageal cancer resection. Can Japanese results be reproduced in Western Centers? Arch Surg 2012, 147:738-745.

17. Cunningham SC, Kamangar F, Kim MP, Hammoud S, Haque R, Maitra A, Montgomery E, Heitmiller RE, Choti MA, Lillemoe KD, Cameron JL, Yeo CJ, Schulick RD: Survival after gastric adenocarcinoma resection: eighteenyear experience at a single institution. J Gastrointest Surg 2005, 9:718-725.

18. Marrelli D, Pedrazzani C, Morgagni P, de Manzoni G, Pacelli F, Coniglio A Marchet A, Saragoni L, Giacopuzzi S, Roviello F: Changing clinical and pathological features of gastric cancer over time. Br J Surg 2011 98:1273-1283.

19. Karpeh MS, Leon L, Klimstra D, Brennan MF: Lymph node staging in gastric cancer: is location more important than number? An analysis of 1038 patients. Ann Surg 2000, 232:362-371.
20. Inoue K, Nkane Y, Michiura T, Nakai K, Sato M, Okumura S, Yamamichi K, Okamura S, Imabayashi N: Trends in long-term survival following surgery for gastric cancer: a single institution experience. Oncol Rep 2004, 11:459-464.

21. Jähne J, Piso P, Meyer HJ: 1114 total gastrectomies in the surgical treatment of primary gastric adenocarcinoma: a 30-year single institution experience. Hepatogastroenterology 2001, 48:1222-1226.

22. Doglietto GB, Pacelli F, Caprino P, Bossola M, Di Stasi C: Pancreas-preserving total gastrectomy for gastric cancer. Arch Surg 2000, 135(1):89-94.

23. Pacelli F, Bossola M, Rosa F, Tortorelli AP, Papa V, Doglietto GB: Is malnutrition still a risk factor of postoperative complications in gastric cancer surgery? Clin Nutr 2008, 27:398-407.

24. Rosa F, Bossola M, Pacelli F, Alfieri S, Doglietto GB: Malnutrition and postoperative complications in abdominal surgery. Ann Surg 2011, 254:666-667.

25. Kim JP, Lee JH, Kim SJ, Yu HJ, Yang HK: Clinicopathologic characteristics and prognostic factors in 10783 patients with gastric cancer. Gastric Cancer 1998, 1:125-133.

26. Hundahl SA, Phillips JL, Menck HR: The National Cancer Data Base Report on poor survival of US gastric carcinoma patients treated with gastrectomy: Fifth Edition American Joint Committee on Cancer staging, proximal disease, and the 'different disease' hypothesis. Cancer 2000, 88:921-932.

27. Smith DD, Schwarz RR, Schwarz RE: Impact of total lymph node count on staging and survival after gastrectomy for gastric cancer: data from a large US-population database. J Clin Oncol 2005, 23:7114-7124.

28. Songun I, Putter $H$, Kranenbarg EM, Sasako M, van de Velde CJ: Surgical treatment of gastric cancer: 15-year follow-up results of the randomised nationwide Dutch D1D2 trial. Lancet Oncol 2010, 11:439-449.

29. Akoh JA, Macintyre IM: Improving survival in gastric cancer: review of 5-year survival rates in English language publications from 1970. $\mathrm{Br} \mathrm{J}$ Surg 1992, 79:293-299.

30. Memon MA, Subramanya MS, Khan S, Hossain MB, Osland E, Memon B: Meta-analysis of D1 versus D2 gastrectomy for gastric adenocarcinoma. Ann Surg 2011, 253(5):900-911.

31. Sasako M: Principles of surgical treatment for curable gastric cancer. J Clin Oncol 2003, 21(23):274s-275s

32. Sano $T$, Sasako M, Yamamoto $S$, Nashimoto A, Kurita A, Hiratsuka M, Tsujinaka T, Kinoshita T, Arai K, Yamamura Y, Okajima K: Gastric cancer surgery: morbidity and mortality results from a prospective randomized controlled trial comparing D2 and extended para-aortic lymphadenectomy: Japan Clinical Oncology Group Study 9501. J Clin Oncol 2004, 22(14):2767-2773.

33. Siewert JR, Kestlmeier R, Busch R, Böttcher K, Roder JD, Müller J, Fellbaum C, Höfler H: Benefit of D2 lymph node dissection for patients with gastric cancer and pN0 and pN1 lymph node metastases. Br J Surg 1996, 83(8):1144-1147.

34. Pacelli F, Doglietto GB, Bellantone R, Alfieri S, Sgadari A, Crucitti F: Extensive versus limited lymph node dissection for gastric cancer: a comparative study of 320 patients. Br J Surg 1993, 80(9):1153-1156.

35. Degiuli M, Sasako M, Calgaro M, Garino M, Rebecchi F, Mineccia M, Scaglione D, Andreone D, Ponti A, Calvo F, Italian Gastric Cancer Study Group: Morbidity and mortality after D1 and D2 gastrectomy for cancer: interim analysis of the Italian Gastric Cancer Study Group (IGCSG) randomized surgical trial. Eur J Surg Oncol 2004, 30(3):303-308.

36. Edwards P, Blackshaw JR, Lewis WG, Barry JD, Allison MC, Jones DR: Prospective comparison of D1 vs modified D2 gastrectomy for carcinoma. Br J Cancer 2004, 90(10):1888-1892.

37. Rosa F, Tortorelli AP, Alfieri S, Doglietto GB: Lymph node ratio for gastric cancer: useful instrument or just an expedient to retrieve fewer lymph nodes? Ann Surg 2014, 259:e65

38. Soreide JA, van Heerden JA, Burgart $L$, Donohue JH, Sarr MG, Ilstrup DM: Surgical aspects of patients with adenocarcinoma of the stomach operated on for cure. Arch Surg 1996, 131:481-486. discussion 486-488.

39. Sanchez-Bueno F, Garcia-Marcilla JA, Perez-Flores D, Perez-Abad JM, Vicente R, Aranda F, Ramirez P, Parrilla P: Prognostic factors in a series of 297 patients with gastric adenocarcinoma undergoing surgical resection. $\mathrm{Br}$ J Surg 1998, 85:255-260.

40. Piso $P$, Werner $U$, Lang $H$, Mirena $P$, Klempnauer J: Proximal versus distal gastric carcinoma-what are the differences? Ann Surg Oncol 2000, 7:520-525.

41. Pacelli F, Papa V, Caprino P, Sgadari A, Bossola M, Doglietto GB: Proximal compared with distal gastric cancer: multivariate analysis of prognostic factors. Am Surg 2001, 67:697-703. 
42. Pacelli F, Cusumano G, Rosa F, Marrelli D, Di Cosmo M, Cipollari C, Marchet A, Scaringi S, Rausei S, di Leo A, Roviello F, de Manzoni G, Nitti D, Tonelli F, Doglietto GB: Multivisceral Resection for Locally Advanced Gastric Cancer: an Italian Multicenter Observational Study (On behalf of the Italian Research Group for Gastric Cancer - IRGGC). JAMA Surg 2013, 148:353-360.

43. Catalano V, Labianca G, Beretta G, Gatta G, de Braud F, Van Cutsem E: Gastric cancer. Crit Rev Oncol Hematol 2009, 71:127-164.

doi:10.1186/1477-7819-12-217

Cite this article as: Rosa et al:: Trends in clinical features, postoperative outcomes, and long-term survival for gastric cancer: a Western experience with 1,278 patients over 30 years. World Journal of Surgical Oncology 2014 12:217.

\section{Submit your next manuscript to BioMed Central and take full advantage of:}

- Convenient online submission

- Thorough peer review

- No space constraints or color figure charges

- Immediate publication on acceptance

- Inclusion in PubMed, CAS, Scopus and Google Scholar

- Research which is freely available for redistribution 